Jurnal Pengabdian Masyarakat

vol.1 no.1 Oktober 2017

\title{
EFEKTIFITAS BEKAM TERHADAP PENURUNAN TEKANAN DARAH PADA PENDERITA HIPERTENSI
}

\author{
Roni Saputra $^{1)}$, Yulia Febrianita ${ }^{2)}$, Kiki Parmanda ${ }^{3)}$ \\ 1) Program Studi D III Keperawatan \\ 2) Fakultas Kedokteran dan Ilmu Kesehatan Universitas Abdurran \\ Ronisaputra1982@gmail.com
}

\begin{abstract}
Treatment of cupping has long been practiced by people of the time of BC to modern times today one of the treatment that can be done with Cupping is Hypertension. Treatment of hypertension with Cupping is one method of treatment of non-pharmacological hypertension. The method used in this devotion is to do Cupping therapy done to the community of Siak Hulu Village Kabar, by way of checking blood pressure before in Cupping and blood pressure examination after in Bekam. The result of the community service activity of blood pressure changes in which patient prior to the blood pressure of patient $140 / 90 \mathrm{mmHg}$ and after the blood pressure was done 130/95 mmHg. The conclusion of this devotion activity is done for 3 times in patients with hypertension with the same patients, this devotion activity is very beneficial by patient of Hipertensi village Siak Hulu Kab Kampar.
\end{abstract}

Keywords: Cupping, Hypertension

\begin{abstract}
ABSTRAK
Pengobatan bekam telah lama di praktekan oleh masyarakat zaman sebelum masehi hingga zaman moderen sekarang ini salah satu pengobatan yang bisa dilakukan dengan Bekam adalah Hipertensi. Pengobatan hipertensi dengan Bekam merupakan salah satu metode pengobatan Hipertensi non farmakologi. Metode yang digunakan dalam pengabdian ini adalah dengan melakukan terapi Bekam yang dilakukan kepada masyarakat Desa Siak Hulu Kab Kampar, dengan cara melakukan pemeriksaan tekanan darah sebelum di Bekam dan pemeriksaan tekanan darah setelah di Bekam. Hasil dari kegiatan pengabdian masyarakat terjadinya perubahan tekanan darah pada pasien yang mana sebelum dilakukan pembekaman tekanan darah pasien 140/90 mmHg dan setelah dilakukan pembekaman terjadi penurunan tekanan darah 130/95 mmHg. Kesimpulan kegiatan pengabdian ini dilakukan selama 3 kali pada pasien penderita Hipertensi dengan pasien yang sama, kegiatan pengabdian ini sangat dirasakan manfaatnya oleh pasien Hipertensi desa Siak Hulu Kab Kampar
\end{abstract}

Kata Kunci : Bekam, Hipertensi 
Jurnal Pengabdian Masyarakat

vol.1 no.1 Oktober 2017

\section{PENDAHULUAN}

Bekam adalah metode pengobatan dengan metode tabung atau gelas yang ditelungkupkan pada permukaan kulit agar menimbulkan bendungan lokal. Terjadinya bendungan lokal disebabkan oleh tekanan negatif dari dalam dalam tabung yang sebelumnya benda-benda dibakar dan dimasukan kedalam tabung agar terjadi pengumpulan darah lokal ( Umar, 2010 )

Dasar pengobatan Bekam ini adalah dari Hadist Nabi Muhammad SAW yaitu: “ Kesembuhan itu terdapat dalam tiga hal yaitu, minum madu, sayatan alat bekam, dan kay. Sesungguhnya aku melarang umatku melakukan kay" ( Shohibul Bukhori, Athibb I jus hal 5680 ). Hadist inilah yang banyak menjadi landasan pengobatan Bekam.

Secara alami tubuh manusia selalu melakukan penyeimbangan terhadap apa yang terjadi didalam tubuh itu sendiri, tetapi apa bila ketidak seimbangan di dalam tubuh terlalu berlebihan makan tubuh juga tidak mampu melakukan penyeimbangan dengan sendirinya, maka di perlukan rangsangan dari luar tubuh dengan tujuan untuk membantu tubuh itu sendiri. Salah satu bentuk ketidak seimbangan adalah kelebihan dalam tubuh atau kekurangan dalam tubuh seperti Hipertensi, ini merupakan salah satu bentuk yang berlebihan didalam tubuh.

Hepertensi merupakan suatu adalah suatu keadaan dimana tekanan darah meningkat melebihi batas normal. Dan kebanyakan masyarakat tidak menyadari bahwa kondisi tekanan daran dalam tubuh telah meningkat atau sebaliknya hal ini disebabkan oleh banyak faktor salah satunya adalah faktor makan.

Hasil Riset Kesehatan Dasar (Riskesdas) 2007 menunjukkan, sebagian besar kasus hipertensi di masyarakat belum terdiagnosis. Hal ini terlihat dari hasil pengukuran tekanan darah pada usia 18 tahun ke atas ditemukan prevalensi hipertensi di Indonesia sebesar 31,7\%, dimana hanya $7,2 \%$ penduduk yang sudah mengetahui memiliki hipertensi dan hanya $0,4 \%$ kasus yang minum obat hipertensi. Ini menunjukkan, $76 \%$ kasus hipertensi di masyarakat belum terdiagnosis atau $76 \%$ masyarakat belum mengetahui bahwa mereka menderita hipertensi".

Untuk propinsi Riau pada tahun 2012 kasus Hipertensi banyak diderita oleh umur 45-54 tahun dengan 892 kasus sedangkan dari jenis kelamin perempuan sebanyak 1.846 kasus lebih tingggi dari pada laki-laki 1.488 kasus ( Profil Riau 2012 )

\section{METODE}

Pengabdian ini dilaksanakan pada tanggal 9,16,23 November 2016 di Desa Siak Hulu Kab Kampar yang bertempat di Masjid Syuhada Dusun III Desa Siak Hulu, dalam pengabdian ini bahan yang di gunakan adalah gelas-gelas kop sebagai median untuk membekam.

Pada pengabdian ini pendekatan dalam pengobatan pada pasien Hipertensi adalah pendekatan non farmakologi yaitu pendekatan pengobatan yang tidak mengunakan obat medis. Variabel yang diamati yaitu tekanan darah pasien, yaitu tekanan darah pasien sebelum di Bekam dan setelah dilakukan pembekaman dan dari hasil pencatatan tekanan darah terjadi perubahan yaitu berbeda antara sebelum di bekam dan sesudah di bekam 
Jurnal Pengabdian Masyarakat

vol.1 no.1 Oktober 2017

\section{HASIL DAN PEMBAHASAN}

Data hasil tekanan darah sebelum dan sesudah di bekam.

Pembekaman 1

\begin{tabular}{|l|l|l|l|}
\hline No & Nama & PRE & POST \\
\hline 1 & Yazid & $150 / 110 \mathrm{mmHg}$ & $140 / 100 \mathrm{mmHg}$ \\
\hline 2 & Datuk Pandau & $160 / 100 \mathrm{mmHg}$ & $140 / 95 \mathrm{mmHg}$ \\
\hline 3 & Darwis. U & $170 / 100 \mathrm{mmHg}$ & $160 / 100 \mathrm{mmHg}$ \\
\hline 4 & Malik & $140 / 100 \mathrm{mmHg}$ & $140 / 90 \mathrm{mmHg}$ \\
\hline 5 & Nurdi & $180 / 110 \mathrm{mmHg}$ & $170 / 100 \mathrm{mmHg}$ \\
\hline 6 & Zulkarnain & $160 / 100 \mathrm{mmHg}$ & $145 / 90 \mathrm{mmHg}$ \\
\hline 7 & Iskandar & $140 / 100 \mathrm{mmHg}$ & $140 / 90 \mathrm{mmHg}$ \\
\hline 8 & Zahari & $150 / 100 \mathrm{mmHg}$ & $140 / 90 \mathrm{mmHg}$ \\
\hline 9 & Linus & $150 / 100 \mathrm{mmHg}$ & $140 / 95 \mathrm{mmHg}$ \\
\hline 10 & Roli & $140 / 90 \mathrm{mmHg}$ & $140 / 90 \mathrm{mmHg}$ \\
\hline & & & \\
\hline
\end{tabular}

Pembekaman 2

\begin{tabular}{|l|l|l|l|}
\hline No & Nama & PRE & POST \\
\hline 1 & Yazid & $150 / 110 \mathrm{mmHg}$ & $140 / 100 \mathrm{mmHg}$ \\
\hline 2 & Datuk Pandau & $160 / 100 \mathrm{mmHg}$ & $140 / 95 \mathrm{mmHg}$ \\
\hline 3 & Darwis. U & $170 / 100 \mathrm{mmHg}$ & $165 / 95 \mathrm{mmHg}$ \\
\hline 4 & Malik & $140 / 100 \mathrm{mmHg}$ & $140 / 85 \mathrm{mmHg}$ \\
\hline 5 & Nurdi & $170 / 110 \mathrm{mmHg}$ & $160 / 100 \mathrm{mmHg}$ \\
\hline 6 & Zulkarnain & $160 / 100 \mathrm{mmHg}$ & $150 / 90 \mathrm{mmHg}$ \\
\hline 7 & Iskandar & $140 / 100 \mathrm{mmHg}$ & $140 / 90 \mathrm{mmHg}$ \\
\hline 8 & Zahari & $150 / 100 \mathrm{mmHg}$ & $140 / 100 \mathrm{mmHg}$ \\
\hline 9 & Linus & $150 / 100 \mathrm{mmHg}$ & $140 / 95 \mathrm{mmHg}$ \\
\hline 10 & Roli & $140 / 90 \mathrm{mmHg}$ & $140 / 90 \mathrm{mmHg}$ \\
\hline
\end{tabular}


Jurnal Pengabdian Masyarakat

vol.1 no.1 Oktober 2017

Pembekaman 3

\begin{tabular}{|l|l|l|l|}
\hline No & Nama & PRE & POST \\
\hline 1 & Yazid & $140 / 100 \mathrm{mmHg}$ & $130 / 95 \mathrm{mmHg}$ \\
\hline 2 & Datuk Pandau & $160 / 100 \mathrm{mmHg}$ & $140 / 95 \mathrm{mmHg}$ \\
\hline 3 & Darwis. U & $170 / 100 \mathrm{mmHg}$ & $155 / 100 \mathrm{mmHg}$ \\
\hline 4 & Malik & $140 / 100 \mathrm{mmHg}$ & $140 / 90 \mathrm{mmHg}$ \\
\hline 5 & Nurdi & $170 / 110 \mathrm{mmHg}$ & $160 / 100 \mathrm{mmHg}$ \\
\hline 6 & Zulkarnain & $150 / 100 \mathrm{mmHg}$ & $145 / 90 \mathrm{mmHg}$ \\
\hline 7 & Iskandar & $140 / 100 \mathrm{mmHg}$ & $140 / 90 \mathrm{mmHg}$ \\
\hline 8 & Zahari & $150 / 100 \mathrm{mmHg}$ & $140 / 90 \mathrm{mmHg}$ \\
\hline 9 & Linus & $140 / 100 \mathrm{mmHg}$ & $130 / 95 \mathrm{mmHg}$ \\
\hline 10 & Roli & $140 / 90 \mathrm{mmHg}$ & $130 / 90 \mathrm{mmHg}$ \\
\hline
\end{tabular}

1. Pasien yang dijadikan sasaran kegiatan rata-rata mempunyai tekanan darah yang tinggi atau hipertensi, sedangkan untuk tekanan darah normal menuru WHO adalah 120/80 mmHg $130 / 90 \mathrm{mmHg}$

2. Untuk mendapatkan hasil dari tujuan kegiatan ini maka dilakukan pemeriksaan tekanan darah sebelum dibekam dan dilakukan pemeriksaan tekanan darah sesudah dilakukan pembekaman

3. Terjadi penurunan tekanan darah pada pasien yang hipertensi setelah dilakukan pembekaman hal ini membutikan hasil penelitian, "Efektifitas terapi bekam terhadap penurunan tekanan darah pada penderita Hipertensi di Rumah Sakit X Pekanbaru Riau 2013", "Pengaruh bekam terhadap tekanan darah pada pasien Hipertensi di Klinik Bekam X di Jakarta tahun 2016", "Efektifitas terapi bekam terhadap penurunan tekanan darah pada penderita hipertensi primer di RS X Riau 2015"

4. Pada saat pelaksanaan pasien yang menjadi sasaran dari awal pelaksanaan sama dengan sampai akhir pelaksanaan, sehingga dapat memberikan gambaran perubahan tekanan darah pada pasien yang sama

5. Pada saat pelaksanaan pembekaman pada pasien Hipertensi di Desa Siak Hulu Kab Kampar tidak ada ditemukan efek samipng dari hasil pembekaman seperti, lemas, rasa ngatuk yang berlebihan, mual, pingsan dll. Sedangkan untuk penggumaa alat bekam sebelum dipakai terlebih dahulu di sterilkan dengan penggunaan $\mathrm{O} 2$ untuk menghinadri penularan penyakit 
Jurnal Pengabdian Masyarakat

vol.1 no.1 Oktober 2017

\section{PHOTO KEGIATAN}

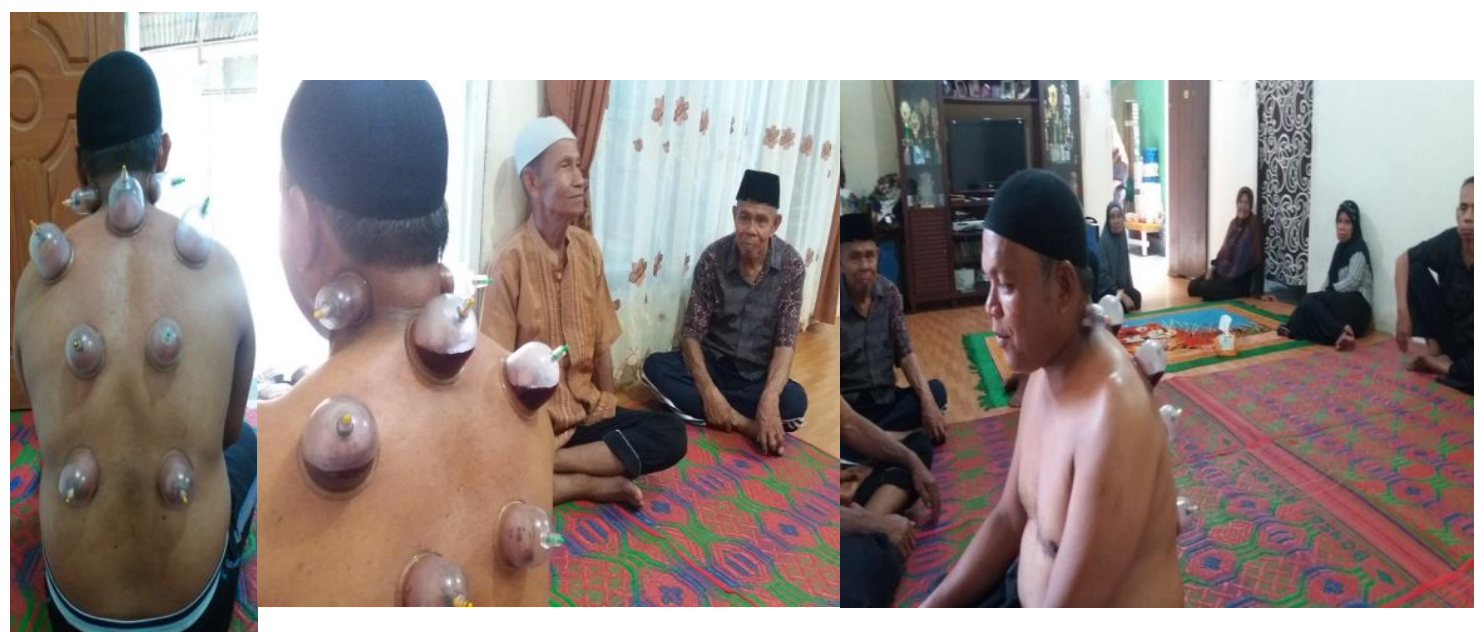

Gambar 1 Proses Bekam Kepada Masyarakat

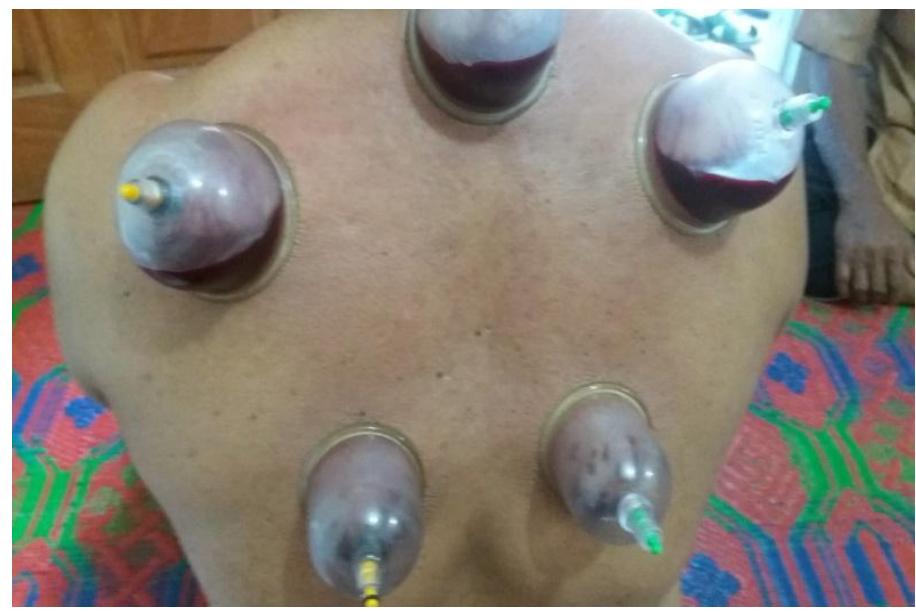

Gambar 2 Proses Bekam Kepada Masyarakat

\section{KESIMPULAN}

a. Kegiatan pengabdian masyarakat ini dilakukan selama tiga kali kepada pasien yang menderita Hipertensi di Desa Siak Hulu Kab Kampar

b. Kegiatan pengabdian masyarakat ini berjalan dengan baik dan lancar sesuai yang dijadwalkan

c. Kegiatan pengabdian masyarakat ini sangat dirasakan manfaatnya bagi pasien penderita Hepertensi. 
Jurnal Pengabdian Masyarakat

vol.1 no.1 Oktober 2017

\section{DAFTAR PUSTAKA}

[1] Abdullah Fattah ( 2010 ) Shahih Thibun nabawi. Jakarta. Pustaka

[2] Imam Ahmad Sya`ban ( 2012 ) Ensiklopedi Pengobatan Islam. Solo. Pustaka Arafah

[3] Ali Ridho, Ahmad (2013) Bekam Sinergi. Solo Aqwamedika

[4] Umar Wadda` ( 2012 ) Sembuh dengan satu titik. Solo. Al - Qowam

[5] Chici (2013) Efektifitas Bekam terhadap penurunan Tekanan darah Pada penderita Hipertensi di RS Zainab Pekanbaru. Tulisan tidak dipublikasikan

[6] Razak, Ahmad Saraf ( 2012 ) Al Usus Al- 'Ilmiyyah lil Mu`jizah An Nabawiyyah Al Hijamah. Surakarta. Thibia 